\title{
Study of comparison of maternal and fetal outcome of elective repeat caesarean versus vaginal birth in women after one prior lower segment caesarean section
}

\author{
Latika $^{1}$, Gurcharan Kaur ${ }^{2}$, Reetu Hooda ${ }^{1}$, Sukhbir Singh ${ }^{3}$
}

\author{
${ }^{1}$ Department of Obstetrics \& Gynecology, PT. B. D. Sharma, PGIMS, Rohtak, Haryana, India \\ ${ }^{2}$ Department of Obstetrics \& Gynecology, Kasturba Hospital, New Delhi, India \\ ${ }^{3}$ Department of Hospital Administration cum Deputy Medical Superintendent, PT. B. D. S. PGIMS, Rohtak, Haryana, \\ India
}

Received: 09 March 2015

Accepted: 23 March 2015

\author{
*Correspondence: \\ Dr. Latika, \\ E-mail: latika.duhan@gmail.com
}

Copyright: () the author(s), publisher and licensee Medip Academy. This is an open-access article distributed under the terms of the Creative Commons Attribution Non-Commercial License, which permits unrestricted non-commercial use, distribution, and reproduction in any medium, provided the original work is properly cited.

\begin{abstract}
Background: Caesarean section is almost one of the oldest operation in surgery with its origin lost in antiquity and ancient mythology. A heightened awareness must occur regarding the decision to perform the first caesarean section. Therefore, a study was planned to compare maternal and perinatal outcome between VBAC and repeat elective LSCS in prior one LSCS patients and their complications.

Methods: The study was undertaken in the department of Obstetrics and Gynecology at Kasturba hospital, Delhi. Total of one hundred (100) cases of previous one LSCS who were eligible for vaginal delivery were recruited and randomized in two groups (VBAC and repeat elective LSCS). Each group was having fifty (50) patients and prospective study was performed.

Results: It was observed that majority of the patients in group I (56\%) and group II (40\%) were in the age group of 20 to 24 years. Majority of the participants in both the groups were Muslims and majority of them were illiterate. Most of them were in the 39 to 40 weeks of gestation at the time of admission in the hospital. It was found that maximum number of neonates in Group I (80\%) \& Group II (76\%) weighed between 2501-3000 grams. No maternal or perinatal death observed.

Conclusions: Vaginal Birth After Caesarean section (VBAC) has always remained a domain of controversies and dilemma in obstetrics. However with improved maternity care, close fetal monitoring and institutional delivery for a previous one caesarean section, VBAC is considered safer than repeat elective caesarean section in a carefully selected patient.
\end{abstract}

Keywords: Caesarean section, VBAC, LSCS, Neonate

\section{INTRODUCTION}

Caesarean section is almost one of the oldest operation in surgery with its origin lost in antiquity and ancient mythology. The literature is full of extensive reports suggesting a gradual but steady rise in incidence of cesarean sections. In the recent years, change in the type of uterine incision combined with advances in technology allows continuous and accurate monitoring of fetus and mother during trial of vaginal delivery after caesarean. Efforts to encourage vaginal birth after caesarean appear to be the most productive approach to lowering the caesarean rate. The main risk in post caesarean pregnancy is the danger of rupture of scar. The review of literature is 
full of studies which clearly show that the incidence of rupture of lower uterine segment scar in patient having a VBAC is very low, $0.3 \%$ (Phelan et.al., 1989) ${ }^{1} 0.49 \%$ (Holland et.al., 1992) ${ }^{2}$ 0.7\% (Zelop et.al., 1999). ${ }^{3}$ When vaginal birth after caesarean section is successful, it is associated with less morbidity than repeat caesarean section. The advantages include avoidance of repeat caesarean section, fewer blood transfusions, fever, postpartum infections and shorter hospital stay. Those patients who fail VBAC are at increased risk of infections and morbidity. Infants born by repeat caesarean delivery after failed VBAC also have increased rates of infections. It is also true that caesarean section carries somewhere between 5 to 10 times increased risk as compared to vaginal delivery (Ritchie 1995) ${ }^{4}$ despite of all advances in surgery, availability of blood, aseptic techniques and newer antibiotics. A heightened awareness must occur regarding the decision to perform the first caesarean section. The obstetricians must consciously consider the impact of 'once a caesarean, always a scar'.

Therefore, a study was planned to compare maternal and perinatal outcome between VBAC and repeat elective LSCS in prior one LSCS patients and their complications.

\section{Aim and objectives}

- To study maternal and fetal outcome of vaginal delivery after caesarean (Group I) and in repeat elective LSCS (Group II) in previous one LSCS patient and to compare maternal and fetal outcomes among both groups.

\section{METHODS}

The study was undertaken in the department of Obstetrics and Gynecology at Kasturba hospital, Delhi. Total of one hundred (100) cases of previous one LSCS who were eligible for vaginal delivery were recruited and randomized in two groups (VBAC and repeat elective LSCS). Each group was having fifty (50) patients and prospective study was performed. In all cases, a detailed history was taken with special emphasis on past obstetric history, indication of previous LSCS, whether elective or emergency LSCS, stage of labour at which it was done, any intra operative or post-operative complication, history of any blood transfusion or wound sepsis, neonatal outcome in terms of baby's birth weight, APGAR score, NICU admission and discharge. Relevant past, personal and family history was also elicited. Routine antenatal investigations and any special investigation whenever indicated were done. A detailed general and systemic examination was done followed by detailed obstetrical examination. Patients were instructed very carefully to report to the hospital immediately in case of any abdominal pain, any vaginal bleeding, abnormal fetal movements, leaking per vaginum or any fainting attacks. Patients attending ANC clinic regularly were admitted 38 weeks or earlier if there were any associated complications. The per vaginal examination was done in all cases at 38 weeks or whenever patient went in labor. All subjects with prior one LSCS who were eligible for vaginal delivery were randomized into groups after taking well informed and written consent explaining possibility of emergency LSCS in patients who undergo TOLAC.

Group-I: Cases for vaginal delivery.

Group-II: Cases for repeat elective caesarean section.

\section{Inclusion criteria}

The booked patients with previous one LSCS, single live fetus, cephalic presentation, adequate pelvis (No CPD) and have reached 38 week gestation were included in the study.

\section{Exclusion criteria}

The patients having more than one caesarean birth, CPD, APH, Vertical, inverted T, classical incision of previous caesarean section, previous uterine surgery such as hysterotomy or previous myomectomy, cervicopexy, Manchester repair, previous uterine perforation were excluded from the study.

\section{Cases for vaginal delivery}

The patients who were kept for trial of vaginal delivery, their blood were cross matched. An intravenous line was started. Patients were followed and closely monitored. Any maternal or fetal complication was noted and treated accordingly. All patients with successful vaginal delivery were observed in the immediate puerperium for any complications. If during trial of vaginal delivery patient developed scar tenderness, or signs of imminent rupture, uterine inertia, unsatisfactory progress of labour, foetal distress, cord prolapse than an emergency LSCS was done.

\section{Cases for repeat elective LSCS}

In this group of patients, repeat elective LSCS was planned after 38 weeks. Operation was done under spinal or general anesthesia. Lower segment caesarean section was done in all cases. All cases were followed up in the postoperative period for any complications. Antibiotics were given prophylactically in all postoperative patients. Hemoglobin estimation and routine urine examination was done in all patients post operatively. The total duration of stay of patient in hospital after a repeat caesarean section was recorded.

\section{Care of newborn}

Immediately after birth of baby, routine nasopharyngeal suction was done in all cases. The following points were looked for in: 
i. APGAR score at one minute and five minutes.

ii. Any resuscitative methods employed.

iii. All neonates were examined in details.

\section{Postpartum examination}

At the time of discharge from the hospital, general examination and vaginal examination was done. Patients were followed up after six weeks for examination and advice.

All babies had follow up examination at six weeks postpartum for any complication or advice. At the end of the study, data was compiled and results critically analysed.

\section{Statistical analysis}

Statistical analysis was performed by the $X^{2}$ (Chi-squire) test \& $\mathrm{Z}$ test. A $\mathrm{P}$ value of $<0.05$ was considered statistically significant.

\section{RESULTS}

\section{Details of various parameters of Group I \& II}

It was observed that majority of the patients in Group I $(56 \%)$ and Group II $(40 \%)$ were in the age group of 20 to 24 years. Majority of the participants in both the groups were Muslims and majority of them were illiterate. Most of them were in the 39 to 40 weeks of gestation at the time of admission in the hospital (Table 1).

\section{Comparison of maternal outcome between Group I \& Group II}

It was found that $6 \%$ patients in group I \& $2 \%$ in Group II had developed post-partum hemorrhage. However association wasn't statistically significant ( $P$ value $0.678)$. It was also found that more patients in Group I required blood transfusion than Group II (6\% vs. 4\%). Other variables were also studied and none of them were statistical significant (Table 2).

\section{Comparison of the fetal outcome between Group I \& Group II}

It was found that maximum number of neonates in Group I $(80 \%)$ \& Group II (76\%) weighed between 2501-3000 grams. No statistical difference was noted between two groups (P value 0.293). Further no statistical difference was noted in the APGAR score of neonates of two groups. There was no fetal death in both the groups. Patients as well as babies were followed up till discharge and at 6 weeks follow up visit, no major complication encountered in both (Table 3 ).
Table 1: Details of various parameters of Group I \& Group II.

\begin{tabular}{|lll|}
\hline Parameter & $\begin{array}{l}\text { Group I } \\
\text { (VBAC) }\end{array}$ & $\begin{array}{l}\text { Group II } \\
\text { (Elective } \\
\text { repeat LSCS) }\end{array}$ \\
\hline Age of the participants (years) & & \\
\hline $20-24$ & $28(56 \%)$ & $20(40 \%)$ \\
\hline $25-29$ & $18(36 \%)$ & $20(40 \%)$ \\
\hline $30-34$ & $4(8 \%)$ & $8(16 \%)$ \\
\hline $35-39$ & 0 & $2(4 \%)$ \\
\hline$>40$ & 0 & 0 \\
\hline Total & 50 & 50 \\
\hline Religion of the participant & & \\
\hline Hindu & $15(30 \%)$ & $17(34 \%)$ \\
\hline Muslim & $32(64 \%)$ & $30(60 \%)$ \\
\hline Sikh & $1(2 \%)$ & $3(6 \%)$ \\
\hline Christian & $2(4 \%)$ & 0 \\
\hline Total & 50 & 50 \\
\hline Educational level of the participants & \\
\hline Illiterate & $40(80 \%)$ & $32(64 \%)$ \\
\hline Primary level & $5(10 \%)$ & $7(14 \%)$ \\
\hline Secondary level & $3(6 \%)$ & $5(10 \%)$ \\
\hline Higher education & $2(4 \%)$ & $6(12 \%)$ \\
\hline Total & 50 & 50 \\
\hline Period of gestation (weeks) & & \\
\hline $38-39$ & $14(28 \%)$ & $19(38 \%)$ \\
\hline $39-40$ & $35(70 \%)$ & $31(62 \%)$ \\
\hline$>40$ & $1(2 \%)$ & 0 \\
\hline Total & 50 & 50 \\
\hline Previous obstetric history & $3(6 \%)$ & $3(6 \%)$ \\
\hline Parity & $35(70 \%)$ & $37(74 \%)$ \\
\hline $\begin{array}{l}\text { P1 } \\
\text { P2 } 3\end{array}$ & $12(24 \%)$ & $8(16 \%)$ \\
\hline History of prior VBAC & $3(6 \%)$ & $5(10 \%)$ \\
\hline History of prior APH & $13(26 \%)$ & $8(16 \%)$ \\
\hline $\begin{array}{l}\text { History of PPH, blood } \\
\text { transfusion }\end{array}$ & $4(8 \%)$ & $2(4 \%)$ \\
\hline History of severe preeclampsia & $2(4 \%)$ \\
\hline
\end{tabular}

Table 2: Comparison of maternal outcome between Group I \& Group II.

\begin{tabular}{|lll|}
\hline Characteristic & $\begin{array}{l}\text { Group I } \\
\text { (VBAC) }\end{array}$ & $\begin{array}{l}\text { Group II (Repeat } \\
\text { elective LSCS) }\end{array}$ \\
of patients & $\begin{array}{l}\text { Number of } \\
\text { patients }\end{array}$ \\
\hline Successful outcome & $50(100 \%)$ & $50(100 \%)$ \\
\hline Complications & & \\
\hline Immediate & & \\
a) PPH & $3(6.0 \%)$ & $1(2 \%)$ \\
b) cervical/vaginal tears & $1(2.0 \%)$ & 0 \\
c) Blood transfusions & $3(6.0 \%)$ & $2(4 \%)$ \\
d) Scar dehiscence & $2(4.0 \%)$ & 0 \\
e) Scar rupture & $1(2.0 \%)$ & 0 \\
\hline $\begin{array}{l}\text { Late } \\
\text { a) Febrile morbidity }\end{array}$ & $7(14.0 \%)$ & $8(16 \%)$ \\
b) puerperal sepsis & $2(4.0 \%)$ & 0 \\
c) U.T.I & $2(4.0 \%)$ & $7(14 \%)$ \\
d) Skin incision complications & $3(6.0 \%)$ & $6(12 \%)$ \\
\hline
\end{tabular}


Table 3: Comparison of fetal outcome between Group I \& Group II.

\begin{tabular}{|c|c|c|}
\hline \multirow[t]{2}{*}{ Characteristic } & $\begin{array}{l}\text { Group I } \\
\text { (VBAC) }\end{array}$ & $\begin{array}{l}\text { Group II (Repeat } \\
\text { elective LSCS) }\end{array}$ \\
\hline & No. of babies & No. of babies \\
\hline \multicolumn{3}{|l|}{ Birth weight (grams) } \\
\hline a) $1501-2000$ & 0 & 0 \\
\hline b) $2001-2500$ & $2(4 \%)$ & $4(8 \%)$ \\
\hline c) $2501-3000$ & $40(80 \%)$ & $38(76 \%)$ \\
\hline d) $3001-3500$ & $6(12 \%)$ & $5(10 \%)$ \\
\hline e) $3501-4000$ & $2(4 \%)$ & $3(6 \%)$ \\
\hline APGAR at 5 minute $<7$ & $2(4 \%)$ & $3(6 \%)$ \\
\hline Respiratory distress & $3(6 \%)$ & $2(4 \%)$ \\
\hline TTN & $1(2 \%)$ & $1(2 \%)$ \\
\hline Infections & $1(2 \%)$ & $1(2 \%)$ \\
\hline NICU Stay & $3(6 \%)$ & $2(4 \%)$ \\
\hline Fetal death & 0 & 0 \\
\hline
\end{tabular}

\section{DISCUSSION}

Vaginal Birth After Caesarean section (VBAC) has always remained a domain of controversies and dilemma in Obstetrics. The reasons for increasing caesarean section rates are multifactorial but a recent analysis of caesarean birth epidemic concluded that a practice of elective repeat caesarean section for women with previous caesarean section has been the major contributor to the escalation in the total Caesarean Section rate., However with improved maternity care, close fetal monitoring and institutional delivery for a previous caesarean section, VBAC is considered safer than repeat elective caesarean section in a carefully selected patient. In our study, majority of the patients in Group I (56\%) and Group II (40\%) were in the age group of 20 to 24 years and most of them were Muslims and were illiterate. This fact may be explained on the basis that the Kasturba Hospital, Delhi is located in a Muslim dominated area, thus the majority of the patients were Muslims. Significant association of success of VBAC was noted in patients with history of prior VBAC as compared to patients without history of prior VBAC ( $\mathrm{P}$ value being $<0.0001)$. In few studies ${ }^{7,8}$ it was concluded that history of previous vaginal delivery is a good prognostic indicator of VBAC in current pregnancy. Scar dehiscence was seen in 2 patients $(4 \%)$ and one patient $(2 \%)$ had scar rupture. No Maternal or fetal mortality was observed. Similar incidence of dehiscence in failed TOL has been reported by several studies: Meirer and Porreco $1982^{9}$ (3.1\%), Paul et al., $1985^{10}(3.6 \%)$. When Group I and Group II were compared with each other, it was found that six percent patients in group I\& $8 \%$ in Group II had $\mathrm{PPH}$ and the morbidity due to $\mathrm{PPH}$ was $7 \%$. Slightly lower figure was reported by Naef et al., $1995^{11}(2.71 \%)$ Significantly more women in Group I (VBAC) required blood transfusion than Group II (Elective repeat LSCS) (6\% vs. $4 \%)$ and this finding was comparable with the result of Naef et al., $1995^{11}(11.5 \%$ vs. $4.6 \%, \mathrm{P}$ value $<0.008$ ). It was found that Group II (Elective repeat LSCS Group) patient's had more febrile morbidity than
Group I (VBAC) and the total febrile morbidity was $15 \%$ in our study which is similar to finding of other study. ${ }^{12}$

It was found that incidence of U.T.I and skin incision complications were higher in Group II (Elective repeat LSCS Group) as compared to Group I (VBAC) (14\% vs. $10 \%$ and $12 \%$ vs. $6 \%$ respectively). Hospital stay associated with successful VBAC was less (2 days) as compared to patients in Group II (5 days) \& patients who had emergency LSCS (7-8 days). This finding is consistent with the results of a study carried out by Pramod Kumar ${ }^{13}$ et al. who showed that mean stay of hospital was 1-2 days in cases with vaginal delivery, 8-12 days for cases who had emergency LSCS and 6-8 days for patients who underwent elective repeat LSCS. It was revealed that the mean birth weight in VBAC Group (Group I) was $2784.20 \pm 40.439$ grams \& in elective repeat LSCS Group (Group II) was $2851.40 \pm 48.647$ grams. It was similar to results of study by Ganitha $G^{14}$ who showed in her study mean birth weight of neonates in elective repeat caesarean section group as $30614 \pm 400$ grams as compared to neonates in trial of labour group as $28526 \pm 390$ grams. It was found that very few neonates in Group I \& Group II had APGAR score <7 at 5 minutes in our study and the results were comparable with the study carried out by Doshi et al. ${ }^{15}$ Six percent of neonates in Group I (VBAC) \& four percent of neonates in Group II (Elective repeat LSCS) had respiratory distress. These findings were similar to that of Muhammad Ali et al. ${ }^{16}$ who showed incidence of $7.964 \%$ respiratory distress in VBAC Group as compared to $5.405 \%$ in repeat elective LSCS Group. 2\% neonates in each of Group I (VBAC) \& II (Elective repeat caesarean section) had TTN. However it is concluded by S. S. Trivedi and Manju Puri in a study ${ }^{17}$ that there is fivefold rise of TTN risk in elective repeat caesarean section as compared to that in vaginal delivery. It was observed that one neonate $(2 \%)$ in each of Group I (VBAC) \& II (Elective repeat caesarean section) was admitted in NICU in view of infection. It was consistent with study of Shakti et al. ${ }^{18}$

\section{CONCLUSION}

From present study, it can be concluded that in properly selected patients, a trial of vaginal delivery after a previous one caesarean section constitutes the best obstetrical management. The significance of vaginal delivery is emphasized because of its minimum postpartum morbidity, anesthetic and operative risks. With proper selection, appropriate timing and close supervision by competent staff, trial of vaginal delivery eliminates the need for a large proportion of repeat caesarean sections.

\section{Funding: No funding sources}

Conflict of interest: None declared

Ethical approval: The study was approved by the institutional ethics committee of Kasturba Hospital, New Delhi 


\section{REFERENCES}

1. Phelan JP, Clark SL, Diaz F, Paul RH. Vaginal birth after caesarean. Am J Obstet Gynecol. 1987 Dec;157(6):1510-5.

2. Holland JG, Dupre AR, Blake PG, Martin RW, Martin JN Jr. Trial of labour after caesarean. J Obstet Gynecol. 1992;79:936.

3. Zelop CM, Shipp TD, Repke JT, Cohen A, Caughey $\mathrm{AB}$, Lieberman E. Uterine rupture during induced or augmented labour in gravid women with one prior caesarean delivery. Am J Obstet Gynecol. 1999 Oct;181(4):882-6.

4. Ritchie JWK. Obstetric operations and procedure. In: Whitfield CR, eds. Dewhurst's Textbook of Obstetrics and Gynecology for Postgraduates. 5th ed. Oxford: Blackwell Science; 1995: 392-396.

5. Cunningham Leveno, Bloom Hauth. Caesarean delivery and peripartum hysterectomy. In: Cunningham Leveno, Bloom Hauth, eds. Williams Obstetrics. 23rd ed. New York: McGraw-Hill Professional; 2010: 544.

6. Flamm BL, Goings JR, Liu Y, Wolde-Tsadik G. Elective repeat caesarean delivery versus trial of labour: a prospective multicenter study. Obstet Gynecol. 1994 Jun;83(6):927-32.

7. Whiteside DC, Mahan CS, Cook JC. Factors associated with successful vaginal delivery after caesarean section. J Reprod Med. 1983;28:785.

8. Flamm BL, Geiger AM. Vaginal birth after caesarean delivery: an admission scoring system. Obstet Gynecol. 1997;90:907-10.

9. Meier PR, Porreco RP. Trial of labor following cesarean section: a two-year experience. Am J Obstet Gynecol. 1982;144(6):671-8.

10. Paul RH, Phelan JP, Yeh SY. Trial of labor in the patient with a prior cesarean birth. Am J Obstet Gynecol. 1985;151(3):297-304.

11. Naef W 3rd, Ray MA, Chauhan SP, Roach H, Blake PG, Martin JN Jr. Trial of labor after caesarean delivery with a lower segment, vertical uterine incision: is it safe? Am J Obstet Gynecol. 1995; 172:1666-74.

12. Rosen MG, Dickinson JC, Westhoff CL. Vaginal birth after caesarean: a meta-analysis of morbidity and mortality. Obstet Gynecol. 1991;77:465-70.

13. Pramod Kumar, Poonam Varma, Shivkumar, Arpita Jaiswal. Subjective assessment of LSCS scar site for vaginal birth after caesarean trial and outcome in MGIMS. Int J Biol Med Res. 2012;3(2):1825-9.

14. Ganitha G. Comparative study of immediate fetal outcome following trial of labour versus elective repeat caesarean section in a case of previous L.S.C.S with singleton pregnancy with vertex presentation. J Obstet Gynecol. 2005 Feb;10:2254.

15. Doshi Haresh, Jain Rohit, Vazirani Aarti. Prognostic factors for successful vaginal birth after caesarean section-analysis of 162 cases. J Obstet Gynecol India. 2010 Dec;60(6):498-502.

16. Muhammad Ali, Rashida Hafeez, Mansoor Ahmad. Maternal and fetal outcome: comparison between emergency caesarean section versus elective caesarean section. Prof Med J. 2005 Mar;12(1):32-9.

17. Trivedi SS, Puri M. Elective repeat caesarean section. In: Trivedi SS, Puri M, eds. Management of High Risk Pregnancy: A Practical Approach. 1st ed. New Delhi, India. Jaypee Brothers Medical Pub; 2010: 254-255.

18. Vardhan Shakti, Behera RC, Sandhu GS, Singh Anita, Bandhu HC. Vaginal birth after caesarean delivery. J Obstet Gynecol India. 2006 Jul/Aug;56(4):320-3.

DOI: $10.18203 / 2320-1770 . i j r \operatorname{cog} 20150070$

Cite this article as: Latika, Kaur G, Hooda R, Singh S. Study of comparison of maternal and fetal outcome of elective repeat caesarean versus vaginal birth in women after one prior lower segment caesarean section. Int J Reprod Contracept Obstet Gynecol 2015;4:664-8. 